\title{
Exploration on the cultivation mode of innovative talents in medical-oriented Biomedical Engineering
}

\author{
Bin Liu*, Lei Duan, Songsheng Zhu, Wei Wang, Yuxuan Zhou, Ke Hu, Hao Wu, Xiaoling Wu \\ Department of Biomedical Engineering, School of Basic Medical Sciences \\ Nanjing Medical University \\ Nanjing, China \\ *Bin Liu, sslb_112@hotmail.com
}

\begin{abstract}
In terms of the cultivation in the field of Biomedical Engineering, how to construct the training system of high quality and innovative talents is the urgent requirement of today's society. Nanjing Medical University makes bold attempts and beneficial exploration in construction of professional talents and teaching materials for Biomedical Engineering, practice base construc tion, teaching staff training, training mode reform and other aspects. It further strengthens the combination of biomedical enginee ring industrialization, science and technology development and basic education, constructs the platform of high quality and innovative talents system, establishes the training target of the innovative talents of medical-oriented biomedical engineering, improves the teaching system of medical integration and explores the multi-level and progressive innovation ability training system.
\end{abstract}

Keywords-Medical- oriented; Biomedical engineering; Innovative talent training.

\section{INTRODUCTION}

Biomedical engineering is a comprehensive cross subject that uses engineering technology to solve medical problems. Currently, with regard to biomedical engineering major, the majority of domestic colleges and universities are comprehensive or science and engineering institutions, only a part of them is medical institutions. Science and engineering colleges pay attention to training students' engineering skills, the graduates generally lack the systematic understanding of medical knowledge and they are not very clear about the specific needs of Engineering Technology in the prevention, treatment, diagnosis and other medical fields, so they will be difficult to get a full development in the medical and health related industries [1]. For medical college graduates, they have better medical background, and they are closely related to clinical medicine. They can easily find and has the ability to solve specific problems in clinical, by contrast, medical college biomedical engineering graduates are easier to adapt to the medical and health industry.

\section{The Training TARGET OF MEDiCAL-ORIENTED TALENTS ESTABLISHMENT}

Biomedical engineering is not a simple combination of medical knowledge and engineering, but a combination of the specific needs of the talent market to conduct top-level design, and the organic integration of the relevant subject knowledge to form their own professional characteristics [2]. Therefore, biomedical engineering should give full play to the advantages of medical colleges and universities, and according to the specific situation of students, to understand the actual needs of the medical and health industry and cultivate the students into "medical oriented" biomedical engineering innovative talents on the basis of letting them be familiar with medical knowledge.

\section{The TEACHING System OF “MediCAL SCIENCE AND ENGINEERING INTEGRATION” IMPROVEMENT}

In order to cultivate the talents to medical-oriented talents, we should not only take advantage of medical colleges and universities, but also strengthen the construction of practice teaching demonstration center, build the "medical science and engineering integration" type of curriculum experiment teaching platform and teaching platform, create a team of "medical science and engineering recombination" so as to improve the teaching system and highlight its professional characteristics.

\section{THE CURRICULUM TEACHING PLATFORM CONSTRUCTION}

Medical colleges and universities and their affiliated hospitals are very rich in medical resources, which can provide a good training and comprehensive medical curriculum for the students of the biomedical engineering, make the knowledge structure of the students more perfect and make full use of the advantages of medical resources to achieve the goal of the curriculum teaching of "Medical Engineering integration".

It needs to set up "four adjustments" in the curriculum: that is, to adjust the proportion of medical courses in basic courses; adjust the proportion of the "medical" courses in the professional courses; adjust the proportion of interdisciplinary fusion 
experiment in the experiment course; adjust the proportion of the contents which are in close combination with the graduation design and practice [3].

"Four focuses" are needed in teaching process, namely, the choice of teaching material should pay attention to "medical science in engineering"; the teaching contents should pay attention to "medical science and engineering permeate"; the teaching methods should pay attention to the combination of medical science and engineering; the graduation design and curriculum design should pay attention to "engineering for medical science", to build the curriculum teaching platform with "four focuses", take advantage of medical colleges and universities and to embody the "medical science and engineering integration".

\section{THE PRACTICAL TEACHING PLATFORM CONSTRUCTION}

In order to ensure the medical colleges of engineering practice condition can be improved and to make it possible to meet the clinical requirements for the ability of engineering practice, the major of biomedical engineering needs to strengthen the construction of the Engineering Laboratory and build a basic training platform, [4] comprehensive development and improvement innovative practice teaching platform and make the practical system of this major show the characteristics of medical science and engineering integration, complete engineering and profound medical science [5].

- Basic training. Integrate mathematics, computer science, physics and other science and engineering laboratories; share school complete medical laboratories; enhance students' ability of theory with practice and engineering basic operation skills, which is the premise of "medical science and engineering integration".

- The comprehensive improvement platform. Establish multiple practice bases, affiliated hospitals and comprehensive laboratories which have the cross disciplinary characteristic to enhance the student to solve clinical problems and the ability to digest. This is a very important process of medical science and engineering integration.

- Expand innovation platforms. It includes innovative laboratories and integrated designs and all the students' scientific and technological innovation activities should be carried out in this platform. Students should choose to participate in the topic which is closely related to medical science and take the medical innovation and the application of engineering knowledge as the goal, which is the specific embodiment of the ability of medical engineering integration.

Multiple platforms of the experimental center can organic link and can carry on comprehensive engineering practice training to the students and this is the strong support of "medical-oriented type".

\section{THE "MEDICAL SCIENCE AND ENGINEERING COMPOUND" TEACHING TEAM CONSTRUCTION}

In order to develop "medical-oriented" compound talents, teaching staff should have the following requirements: they should have the ability to digest, have the knowledge background of multi-subject compound and have the consciousness of clinical services. In the professional field, we should take advantage of the excellent medical teachers, and also cooperate with senior engineering and technical personnel and clinicians from the affiliated hospital, combined with professional teachers in the background of science and technology to form the "medical science and engineering compound type" teaching staff.

In addition, to strengthen the cultivation of composite type teachers, for teachers with the background of science and technology, it needs to train them in medical knowledge and encourage them to actively participate in clinical research cooperation; arrange the clinical teachers and the science and engineering teachers to teach the comprehensive experimental lessons to the students to promote the "two-way integration" of their knowledge structure and to cultivate the outstanding teachers who have the integrated knowledge of science, engineering and medical science.

\section{THE CULTIVATION SYSTEM OF THE MULTI-LEVEL AND PROGRESSIVE INVOCATIVE ABILITY EXPLORATION}

The core of "medical-oriented" compound talents cultivation is to cultivate innovation ability, give full play to the advantages of its own resources, build and implement the three stage of progressive innovation ability training system of "deepening and widening, practice training and cognitive experience" (as shown in the figure 1), and combine the students' autonomy and teacher's dominant. 


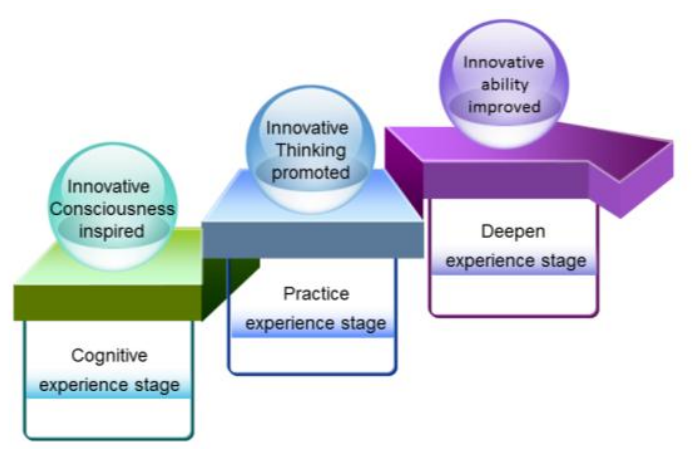

Fig. 1. The three stage of progressive innovation ability training system.

\section{CONCLUSION}

With regard to biomedical engineering talent training, the creative application of the "demand-oriented" training mode is the "medical-oriented" training mode, and biomedical engineering experimental teaching center is the material basis of the training mode. In view of the engineering and technical personnel needs of medical and health related industries, combined with the construction of experimental center, this specialty establishes the target of "Medical oriented" biomedical engineering innovation talents cultivation, improves the "medical integration" teaching system, explores the multi-level and progressive innovation ability training system.

\section{ACKNOWLEDGMENT}

This research was financially supported by Research project of "12th Five-Year Plan" education in Nanjing Medical University (JYY2015077).

\section{REFERENCES}

[1] W. Wang, L. Duan, S. S. Zhu, B. Liu and X. L. Wu, "Deepening Experiment Teaching Demonstration Center Construction, Developing a " Medicaloriented" Biomedical Engineering Innovation Talent" Research and Exploration in Laboratory, vol. 33, pp. 52-55, July 2014.

[2] Q. M. Chen, F. Li, X. Fu, Q. Huang, G. L. Zhang, S. Jin, "Talent Cultivation Mode Discussion on Biomedical Engineering Specialty of Medical Colleges" Science Mosaic, vol. 10, pp. 156-158, October 2011.

[3] Y. Gao, H. Liu, Z. Zhang, “The Development and Innovation of Biomedical Engineering in Hospital” China Medical Devices, vol. 6, pp. 62-65, June 2010.

[4] S.S. Demir, "Biomedical engineering: Integration of research, education and innovation," in Bursa, 2011, pp. II-1.

[5] L. Yuan, "An Analysis about the Relationship between Managing Innovation and Comprehensively Training the Undergraduates of Biomedical Engineering,” Journal of Electrical \& Electronic Engineering Education, February 2005. 